\title{
Real-Time Monitoring of Powder Mixing Dynamics with Spectroscopic PAT-Tools
}

\author{
D. M. KOLLER ${ }^{1}$, N. BALAK ${ }^{1}$, O. SCHEIBELHOFER ${ }^{1}$, J. MOOR ${ }^{1}$, \\ G. HÖRL ${ }^{1}$, N. HEIGL ${ }^{1}$, S. D. FRASER ${ }^{1}$, J. G. KHINAST ${ }^{1,2}$ \\ ${ }_{2}^{1}$ Research Center Pharmaceutical Engineering GmbH, Graz, Austria \\ ${ }^{2}$ Institute for Process and Particle Engineering, Graz University of Technology, Graz, Austria \\ E-mail: daniel.koller@rcpe.at (D. M. Koller),khinast@tugraz.at (J. G. Khinast) \\ Sci Pharm. 2010; 78: 573 \\ doi:10.3797/scipharm.cespt.8.LPAT02
}

The aim of Process Analytical Technology (PAT) is to gain deeper insight in pharmaceutical manufacturing processes, replacing empirical approaches by knowledge-based procedures. A detailed understanding of the key parameters of a process and their impact on the product quality allows companies to "build in quality" instead of "testing it into the final product". From this point of view, PAT has to be tailored for a direct implementation to manufacturing lines to measure in real-time the key parameters of the process.

Here, we present results on real-time quantitative in-line monitoring of powder mixing processes by near-infrared (NIR) spectroscopy [1,2]. Spectral data collection and data analysis was performed in real-time based on partial least squares models developed via dynamic calibration. Different strategies are followed: I) Application of a single reflection probe to determine the mixing endpoint. II) A novel multiple reflectance probe measurement system for a spatially resolved monitoring of the powder flow kinetics within a blender. The parameters from the mixing process are linked to keyparameters of powders, obtained from rheometric investigations based on experimental design.

Beside the batch processes monitored here with NIR spectroscopy, we also introduce hyper spectral imaging for monitoring fast continuous processes and non-invasive product quality analysis of solid dosage forms.

[1] Koller DM, Posch A, Hörl G, Voura C, Radl S, Urbanetz N, Fraser SD, Tritthart W, Reiter F, Schlingmann M, Khinast JG. Continuous Quantitative Monitoring of Powder Mixing Dynamics by Nearinfrared Spectroscopy. Powder Technol. 2010; submitted.

[2] Remy B, Glasser BJ, Khinast JG. The effect of mixer properties and fill level on granular flow in a bladed mixer. AIChE J. 2010, 56: 336-353. doi:10.1002/aic.11979 